2013-12-05

\title{
Stress and Visual Function in Infantile
} Nystagmus Syndrome

\author{
Jones, $\mathrm{PH}$
}

http://hdl.handle.net/10026.1/8351

\subsection{7/iovs. 13-12560}

Investigative Opthalmology \&amp; Visual Science

Association for Research in Vision and Ophthalmology (ARVO)

All content in PEARL is protected by copyright law. Author manuscripts are made available in accordance with publisher policies. Please cite only the published version using the details provided on the item record or document. In the absence of an open licence (e.g. Creative Commons), permissions for further reuse of content should be sought from the publisher or author. 


\title{
Stress and Visual Function in Infantile Nystagmus Syndrome
}

\author{
Philip H. Jones, ${ }^{1}$ Christopher M. Harris,${ }^{2}$ J. Margaret Woodhouse,${ }^{1}$ Tom H. Margrain,${ }^{1}$ \\ Fergal A. Ennis, ${ }^{1}$ and Jonathan T. Erichsen ${ }^{1}$ \\ ${ }^{1}$ School of Optometry and Vision Sciences, Cardiff University, Cardiff, United Kingdom \\ ${ }^{2}$ Centre for Robotics and Neural Systems and Plymouth Cognition Institute, Plymouth University, Plymouth, United Kingdom
}

Correspondence: Jonathan T. Erichsen, School of Optometry and Vision Sciences, Cardiff University, Maindy Road, Cardiff CF24 4HQ, Wales, UK; ErichsenJT@cf.ac.uk.

Submitted: June 7, 2013

Accepted: October 18, 2013

Citation: Jones PH, Harris CM, Woodhouse JM, Margrain TH, Ennis FA, Erichsen JT. Stress and visual function in infantile nystagmus syndrome. Invest Opbthalmol Vis Sci. 2013;54:7943-7951. DOI:10.1167/ iovs.13-12560
Purpose. Infantile nystagmus syndrome (INS) is an involuntary oscillation of the eyes that has been reported to impair vision and worsen under stress. This investigation aimed to measure visual function in terms of visual acuity (VA) and response time (RT), when INS subjects are placed under stress.

Methods. A total of 23 subjects with INS and 20 control subjects performed a 2-alternative forced choice (2AFC) staircase procedure identifying the gap in a Landolt $\mathrm{C}$, under 4 experimental conditions: initial acclimatization (A); task demand (TD), during which subjects received a small electrical shock for every incorrect answer; anticipatory anxiety (AA), during which subjects received a small shock at random intervals; and relaxed (R). Arousal was monitored with galvanic skin conductance (SkC). In addition to VA and eye movements, RTs were recorded.

Results. The SkC was higher in the TD and AA periods and lower during A and R. Shock significantly increased nystagmus amplitude $(P<0.01)$ and intensity $(P<0.007)$, and reduced foveation periods (FPs, $P<0.022$ ). In both groups, VA was not reduced, but showed a slight improvement. However, shock increased RT $(P<0.009)$, and INS subjects were slower than controls $(P<0.0005)$.

Conclusions. Increased arousal ("stress") provoked more intense nystagmus eye movements. As seen in other studies, stress did not reduce VA despite the shorter FPs. Although VA and FP can correlate across subjects, there would appear to be little correlation, if any, within a subject. However, RTs did increase with stress and shorter FPs, which may have an adverse impact on the visual performance of those with INS.

Keywords: visual acuity, arousal, shock, foveation, eye movements, skin conductance, response time
$I^{n}$ nfantile nystagmus syndrome (INS) is an involuntary oscillation of the eyes with an onset at birth, or in the first few postnatal weeks. It is lifelong and currently incurable. In most cases, INS is associated with a congenital bilateral afferent sensory defect (SDINS; e.g., albinism). However, in approximately $20 \%$, no defect is found, ${ }^{1}$ and the nystagmus is described as idiopathic (IINS). Nystagmus per se causes retinal slip, which might be expected to limit vision. However, for subjects with IINS, visual acuity (VA) ranges from normal values $(-0.3$ LogMAR) to severely impaired (1.2 LogMAR). In SDINS, vision often is reduced further depending on the underlying sensory defect (0.2-2 LogMAR in albinism ${ }^{2}$ ). In adults, the nystagmus intensity characteristically depends on eye-in-head position with a region of minimal average velocity, called the "null zone." When present, the null zone often is not straight ahead and, in approximately $25 \%$ of cases, is outside the central gaze region of $\pm 10^{\circ} .{ }^{3}$ In tasks requiring maximum VA, many patients will adopt an abnormal head posture (AHP) to capitalize on their eccentric null zone.

Another common feature of nystagmus is known as the foveation period (FP). This describes the period of time during a nystagmus cycle in which the position of the image of the object of regard on the retina and the retinal slip velocity allow best VA. ${ }^{4-7}$ Previous studies have used position criteria for foveation that vary from $0.5^{\circ}$ to $6^{\circ}, 5,8,9$ with velocity thresholds ranging from $1.67^{\circ} / \mathrm{s}$ to $10^{\circ} / \mathrm{s} .{ }^{5,10,11}$ Many studies use an accepted foveation criterion with an eye position between $\pm 2^{\circ}$ of the target ${ }^{12}$ and a velocity of $\leq 4^{\circ} / \mathrm{s}^{5,8,12,13}$

Nystagmus and visual performance also are sensitive to psychological factors, and many people with this condition anecdotally report reduced vision under demanding and/or stressful conditions. Previous experimental studies have reported that the nystagmus increases in intensity with increased "effort to see" or "fixation attempt,"14-16 or decreases with relaxation. ${ }^{16}$

Intriguingly, it has been reported that nystagmus either is unaffected by visual demand ${ }^{17}$ or actually decreases in intensity. ${ }^{18}$ Both of these studies attribute their findings to visual demand in the absence of stress. Wiggins et al. ${ }^{18}$ reported that stress was minimal in their experimental setup, with subjects having unlimited viewing time for optotypes. They concluded that a more stressful "task demand" may have a detrimental effect on the nystagmus waveform. Tkalcevic and Abel $^{17}$ also suggested that motivating people to do well on a visual task (e.g., to achieve VA good enough to drive) would introduce a psychological stress, with an adverse impact on the 
nystagmus waveform and, hence, presumably VA. Using such a motivational approach, in which poor performance results in negative reinforcement (i.e., has a consequence), Cham et al. ${ }^{19}$ manipulated task demand, and found that nystagmus intensity increased and FPs decreased with stress. However, in their discussion, Cham et al. ${ }^{19}$ point out that their study was not designed to measure VA, as a nonconventional acuity task was employed with optotypes having blurred edges (to increase the visual demand of the task). Moreover, measurements were taken only in the primary position with no optical correction. Cham et al. ${ }^{20}$ also recently demonstrated the changes in nystagmus intensity and foveation duration in subjects with fusional maldevelopment nystagmus syndrome (FMNS).

Although VA often is used as the clinical gold standard of visual performance, it has been proposed that nystagmus also increases the time needed to fixate a peripheral visual target, that is the "slow-to-see" phenomenon. ${ }^{21}$ In normal subjects, a change of fixation usually is achieved by one or two saccadic eye movements, but in the presence of nystagmus, there generally is an increase in latency and positional error. Stress also may increase time-to-see by increasing nystagmus intensity and/or change the waveform itself.

The aim of our study was to investigate specifically the simultaneous effects of stress on nystagmus eye movements and visual function. To do this, we measured VA using conventional psychophysical stimuli and methods, while subjects wore their habitual visual correction and positioned their eyes in their preferred null zone. Response time (RT) to make the discrimination also was measured as a further measure of visual function. This was taken as the length of time subjects took to respond to the visual stimulus from its appearance. The RT (recognition time) has been used previously as a measure of visual function following fourmuscle recession surgery for those with nystagmus. ${ }^{22}$

\section{Methods}

\section{Subjects}

Subjects were recruited from the Research Unit for Nystagmus cohort at Cardiff University. Data were collected from 23 subjects (10 male and 13 female): 19 with idiopathic nystagmus, 3 with ocular albinism, and 1 with oculocutaneous albinism (age range, 19-71; mean $=44$ ). We recruited 20 control subjects from staff and students of the School of Optometry and Vision Sciences, Cardiff University (age range, 21-61; mean =34). Clinical data for all subjects with INS are shown in the Table. All subjects were naive to the experimental procedure. The investigation was done in accordance with the Declaration of Helsinki, and ethical approval was granted by the Cardiff School of Optometry and Vision Sciences Human Research Ethics Committee.

Retinoscopy was performed on every subject to ensure their habitual refractive correction was within \pm 0.50 diopters sphere (DS) of the optimal correction. If the result was greater than this \pm 0.50 DS difference, then the retinoscopy result was used. If subjects did not wear spectacles to correct for a distance refractive error, they performed the task without spectacles. All subjects who performed the task in this way had a mean spherical refractive error of within $\pm 0.50 \mathrm{DS}$, or had a level of amblyopia that was not improved with the use of corrective lenses. This was done to avoid any difficulties involving adaptation to spectacles.

Ophthalmoscopy was done to identify any underlying ocular pathologies other than ocular albinism and nystagmus, and subjects were excluded if there was any sign of another ocular pathology that may affect VA. None of the subjects discussed in this report showed any signs of ocular pathology other than nystagmus and, in a few cases, ocular albinism.

A cover test identified those subjects who had a manifest strabismus and any latent component to their nystagmus. All subjects with manifest strabismus had the strabismic eye occluded during eye movement recording to avoid the fixating eye alternating during recording.

\section{Shock As a Stressor}

Mild electric shock has been shown to cause increases in skin conductance $(\mathrm{SkC})$ and heart rate, both signs of heightened arousal/stress. ${ }^{23-25}$ In our study, stress was created using a transcutaneous electrical nerve stimulation (TENS) machine (Lloyds Pharmacy UK Ltd., Norfolk, UK). The TENS unit generally is used for pain relief and works by interrupting pain signals with the use of topically applied electrical impulses. This TENS machine is available commercially, and consists of two adhesive pads (electrodes) and a central unit. The two electrodes were placed on the subject's dominant arm, one on the forearm and one on the upper arm (Fig. 1A). The TENS device has been shown previously not to interfere directly with the measurement of skin conductance. ${ }^{26}$

The TENS machine had 8 intensity settings (1-8) and 8 mode settings $(\mathrm{A}-\mathrm{H})$. The change in the mode relates to increases in the frequency of the bursts: " $\mathrm{A}$ " being the lowest and " $\mathrm{H}$ " the highest. The maximum current of the TENS is 30 $\mathrm{mA} \pm 20 \%$, with a maximum voltage of $80 \mathrm{~V} \pm 20 \%{ }^{27} \mathrm{Each}$ subject's tolerance to the TENS machine was determined before the first stressed VA measurement. This was done by setting the TENS to mode A and stepping up the intensity one level at a time until subjects either reported that they could not tolerate a higher level, or until level 8 was reached.

\section{Skin Conductance (SkC)}

The SkC was recorded using a Biopac MP30 physiologic amplifier and BSL Pro software version 3.6.7 (Linton Instruments Ltd, UK, CITY, STATE). Two silver chloride electrodes were placed on the first and second fingers of the subject's nondominant hand (Fig. 1B), and recorded at a gain of 2000 at 50 samples per second during the whole recording session. The mean conductance then was computed for each of the four experimental conditions (see Experimental Procedures section). For three subjects with INS and three controls, SkC data were not obtained as a result of technical difficulties in recording from the skin electrodes during the experiment; eye movement and VA data were collected for all subjects in both groups.

The SkC data across individuals were not comparable directly due to different baseline values. For statistical analysis, we normalized the SkC reading by subtracting out each subject's grand mean, so that each subject had a zero mean across the conditions (relative conductance measured in microsiemens $[\mu \mathrm{S}])$.

\section{VA and RT}

The VA was measured in each subject's preferred null zone using a two-alternative forced choice (2AFC) staircase procedure. The subject's task was to identify the gap in a Landolt $\mathrm{C}$ as being on the left or right, and then respond via a button box. The initial size of the stimulus was set at $0.3 \log$ units above clinically measured VA, and the procedure then proceeded in a three up, one down paradigm with a fixed step size of 0.075 LogMAR. Once a criterion of 80 presentations and eight reversals had been met, the staircase continued for two minutes to allow collection of sufficient data at threshold. 
TABLE. Clinical Details for Subjects With INS

\begin{tabular}{|c|c|c|c|c|c|c|c|}
\hline & Age/Sex & $\begin{array}{c}\text { Clinical } \\
\text { Diagnosis }\end{array}$ & $\begin{array}{c}\text { Ocular } \\
\text { Alignment }\end{array}$ & $\begin{array}{c}\text { Null Angle, } \\
\text { deg }\end{array}$ & $\mathbf{R x}$ & $\begin{array}{l}\text { VA, } \\
\text { LogMAR }\end{array}$ & $\begin{array}{c}\text { Waveform } \\
\text { Type }\end{array}$ \\
\hline $\mathrm{RB}$ & 23/M & Idiopathic & Ortho & $10^{\circ}$ & $\begin{array}{l}\text { OD: Plano } \\
\text { OS: }-0.50 \text { DS }\end{array}$ & $\begin{array}{l}\text { OD: } 0.10 \\
\text { OS: } 0.10\end{array}$ & $\mathrm{JR}_{\mathrm{EF}} / \mathrm{JL} \mathrm{L}_{\mathrm{EF}}$ \\
\hline JS & 53/M & Idiopathic & Ortho & $12^{\circ}$ & $\begin{array}{l}\text { OD: }-12.00 /-2.00 \times 32 \\
\text { OS: }-10.50 /-1.00 \times 90\end{array}$ & $\begin{array}{l}\text { OD: } 0.30 \\
\text { OS: } 0.30\end{array}$ & $\mathrm{JL}_{\mathrm{EF}}$ \\
\hline RW & $30 / \mathrm{M}$ & Ocular albinism & Ortho & Primary & $\begin{array}{l}\text { OD: Plano } \\
\text { OS: Plano }\end{array}$ & $\begin{array}{l}\text { OD: } 0.56 \\
\text { OS: } 0.46\end{array}$ & $\mathrm{AP} / \mathrm{PP}_{\mathrm{FS}}$ \\
\hline $\mathrm{RC}$ & 38/M & Ocular albinism & R ET & $5^{\circ}$ & $\begin{array}{l}\text { OD: }+4.25 /-4.50 \times 6 \\
\text { OS: }+5.25 /-5.00 \times 165\end{array}$ & $\begin{array}{l}\text { OD: } 0.48 \\
\text { OS: } 0.26\end{array}$ & $\mathrm{DJ} / \mathrm{PC}$ \\
\hline vO & $28 / \mathrm{F}$ & Idiopathic & Ortho & Primary & $\begin{array}{l}\text { OD: }-1.00 \mathrm{DS} \\
\text { OS: }-0.25 \mathrm{DS}\end{array}$ & $\begin{array}{l}\text { OD: } 0.00 \\
\text { OS: } 0.00\end{array}$ & $\mathrm{PP}_{\mathrm{FS}}$ \\
\hline WL & $48 / \mathrm{F}$ & Idiopathic & Exop & $-5^{\circ}$ & $\begin{array}{l}\text { OD: }-1.50 \mathrm{DS} \\
\text { OS: }-1.50 \mathrm{DS}\end{array}$ & $\begin{array}{l}\text { OD: } 0.40 \\
\text { OS: } 0.40\end{array}$ & $P P_{F S}$ \\
\hline LL & 53/M & Idiopathic & Esop & Primary & $\begin{array}{l}\text { OD: }-0.25 /-0.25 \times 155 \\
\text { OS: }-0.50 /-0.75 \times 110\end{array}$ & $\begin{array}{l}\text { OD: } 0.32 \\
\text { OS: } 0.32\end{array}$ & $J L_{E F} / P_{F S}$ \\
\hline JeSt & $27 / F$ & Idiopathic & Ortho & Primary & $\begin{array}{l}\text { OD: }-1.50 /-1.75 \times 5 \\
\text { OS: }-1.00 /-1.75 \times 175\end{array}$ & $\begin{array}{l}\text { OD: } 0.00 \\
\text { OS: } 0.08\end{array}$ & $J R_{E F}$ \\
\hline MH & $47 / \mathrm{M}$ & Idiopathic & $\mathrm{R}$ hyperp & $10^{\circ}$ & $\begin{array}{l}\text { OD: }+4.50 /-1.00 \times 165 \\
\text { OS: }+3.25 /-1.00 \times 180\end{array}$ & $\begin{array}{l}\text { OD: } 0.38 \\
\text { OS: } 0.36\end{array}$ & $P P_{F S} / D J$ \\
\hline JqA & $46 / \mathrm{F}$ & Idiopathic & Ortho & $5^{\circ}$ & $\begin{array}{l}\mathrm{OD}:+5.50 /-5.00 \times 10 \\
\mathrm{OS}:+4.00 /-5.00 \times 180\end{array}$ & $\begin{array}{l}\text { OD: } 0.26 \\
\text { OS: } 0.30\end{array}$ & $P_{F S}$ \\
\hline GT & $60 / \mathrm{M}$ & Idiopathic & Ortho & Primary & $\begin{array}{l}\text { OD: }-2.00 /-0.50 \times 25 \\
\text { OS: }-0.75 /-0.50 \times 130\end{array}$ & $\begin{array}{l}\text { OD: } 0.52 \\
\text { OS: } 0.40\end{array}$ & $\mathrm{P}_{\mathrm{FS}}$ \\
\hline CT & $54 / \mathrm{F}$ & Idiopathic & R XT & $15^{\circ}$ & $\begin{array}{l}\text { OD: }-5.50 \mathrm{DS} \\
\text { OS: }-5.50 \mathrm{DS}\end{array}$ & $\begin{array}{l}\text { OD: } 0.28 \\
\text { OS: } 0.14\end{array}$ & $\mathrm{P} / \mathrm{DJ}$ \\
\hline KL & $58 / \mathrm{F}$ & Idiopathic & $\begin{array}{l}\text { L XT } \\
\quad \text { (corrected) }\end{array}$ & Primary & $\begin{array}{l}\text { OD: }-0.75 /-0.50 \times 165 \\
\text { OS: }+0.25 /-0.25 \times 180\end{array}$ & $\begin{array}{l}\text { OD: } 0.00 \\
\text { OS: } 0.12\end{array}$ & DJ \\
\hline $\mathrm{JM}$ & $41 / \mathrm{M}$ & Ocular albinism & L ET & Primary & $\begin{array}{l}\text { OD: }+7.75 /-2.75 \times 160 \\
\text { OS: }+7.50 /-2.75 \times 60\end{array}$ & $\begin{array}{l}\text { OD: } 0.56 \\
\text { OS: } 0.92\end{array}$ & PC \\
\hline $\mathrm{CM}$ & $59 / \mathrm{F}$ & Idiopathic & L ET & $-15^{\circ}$ & $\begin{array}{l}\text { OD: Plano } \\
\text { OS: Plano }\end{array}$ & $\begin{array}{l}\text { OD: } 0.50 \\
\text { OS: } 0.60\end{array}$ & $\mathrm{PP}_{\mathrm{FS}}$ \\
\hline MB & $57 / \mathrm{F}$ & Idiopathic & L XT & Primary & $\begin{array}{l}\text { OD: }-0.25 /-1.50 \times 10 \\
\text { OS: }+2.75 /-2.00 \times 17\end{array}$ & $\begin{array}{l}\text { OD: } 0.50 \\
\text { OS: } 0.60\end{array}$ & DJ \\
\hline MT & $67 / F$ & Idiopathic & Ortho & Primary & $\begin{array}{l}\text { OD: }+4.25 /-0.75 \times 30 \\
\text { OS: }+5.50 /-1.25 \times 180\end{array}$ & $\begin{array}{l}\text { OD: } 0.60 \\
\text { OS: } 0.78\end{array}$ & $\mathrm{JL}_{\mathrm{EF}}$ \\
\hline VW & $20 / \mathrm{F}$ & Idiopathic & Alt. ET & $-5^{\circ}$ & $\begin{array}{l}\text { OD: }+2.25 /-3.75 \times 19 \\
\text { OS: }+2.50 /-3.75 \times 161\end{array}$ & $\begin{array}{l}\text { OD: } 0.32 \\
\text { OS: } 0.34\end{array}$ & $\mathrm{JR}_{\mathrm{EF}}$ \\
\hline SW & $67 / \mathrm{F}$ & Idiopathic & Ortho & $5^{\circ}$ & $\begin{array}{l}\text { OD: Plano } \\
\text { OS: Plano/-0.50 } \times 180\end{array}$ & $\begin{array}{l}\text { OD: } 0.40 \\
\text { OS: } 0.40\end{array}$ & DJ \\
\hline LC & 26/M & Idiopathic & L ET & Primary & $\begin{array}{l}\text { OD: }+3.75 /-2.75 \times 165 \\
\text { OS: }+3.75 /-3.25 \times 35\end{array}$ & $\begin{array}{l}\text { OD: } 0.56 \\
\text { OS: } 0.70\end{array}$ & $\mathrm{PP}_{\mathrm{FS}}$ \\
\hline RN & $71 / \mathrm{M}$ & $\begin{array}{l}\text { Oculocutaneous } \\
\text { albinism }\end{array}$ & R ET & Primary & $\begin{array}{l}\text { OD: }+1.75 /-2.00 \times 180 \\
\text { OS: }+2.50 /-2.00 \times 180\end{array}$ & $\begin{array}{l}\text { OD: } 0.84 \\
\text { OS: } 0.60\end{array}$ & DJ \\
\hline DW & $29 / \mathrm{F}$ & Idiopathic & Ortho & Primary & $\begin{array}{l}\text { OD: }-5.00 \text { DS } \\
\text { OS: }-5.00 \text { DS }\end{array}$ & $\begin{array}{l}\text { OD: } 0.00 \\
\text { OS: } 0.00\end{array}$ & $\mathrm{JR}_{\mathrm{EF}}$ \\
\hline $\mathrm{CW}$ & $19 / \mathrm{F}$ & Idiopathic & Ortho & Primary & $\begin{array}{l}\text { OD: Plano } /-0.50 \times 180 \\
\text { OS: Plano/-0.50 } \times 180\end{array}$ & $\begin{array}{l}\text { OD: } 0.40 \\
\text { OS: } 0.40\end{array}$ & $\mathrm{P}$ \\
\hline
\end{tabular}

Ortho, orthophoric; R, right; L, left; ET, esotropia; XT, exotropia; Exop, exophoria; Esop, esophoria; Hyperp, hyperphoria; Alt, alternating; JR jerk right with extended foveation; $\mathrm{JL}_{\mathrm{EF}}$ jerk left with extended foveation; $\mathrm{AP}$, asymmetric pendular; $\mathrm{PP}_{\mathrm{Fs}}$, pseudo pendular with foveating saccades; DJ, dual jerk; PC, pseudo cycloid; $\mathrm{P}_{\mathrm{FS}}$, pendular with foveating saccades; $\mathrm{P}$, pendular.

The stimulus was created with a VSG 2/3 (Cambridge Research Systems, Cambridge, UK). Viewing time was unrestricted, although subjects were asked to respond as quickly and as accurately as possible.

The RT was calculated by the computer program as the time between the stimulus appearing on the monitor and the subject giving their response using the button box.

\section{Experimental Setup}

To ensure that our measurement of acuity was not limited by the resolution of the monitor, a $7 \mathrm{~m}$ distance was required.
Hence, the lab setup consisted of a two-mirror system (Fig. 2). The orientation of a front surface mirror was controlled by a computer-controlled stepper motor, which is capable of driving the mirror through a number of gaze angles to within $1^{\circ} .18$ The center of rotation of the motorized mirror was positioned $40 \mathrm{~cm}$ from the headrest (and, therefore, the subject's head). The angle of the mirror determined the orbital eye position the subject needed to view the stimulus. The mirror was positioned to allow the use of each subject's null zone.

Chin and cheek rests were used to stabilize head movements throughout the investigation. A high quality 21- 


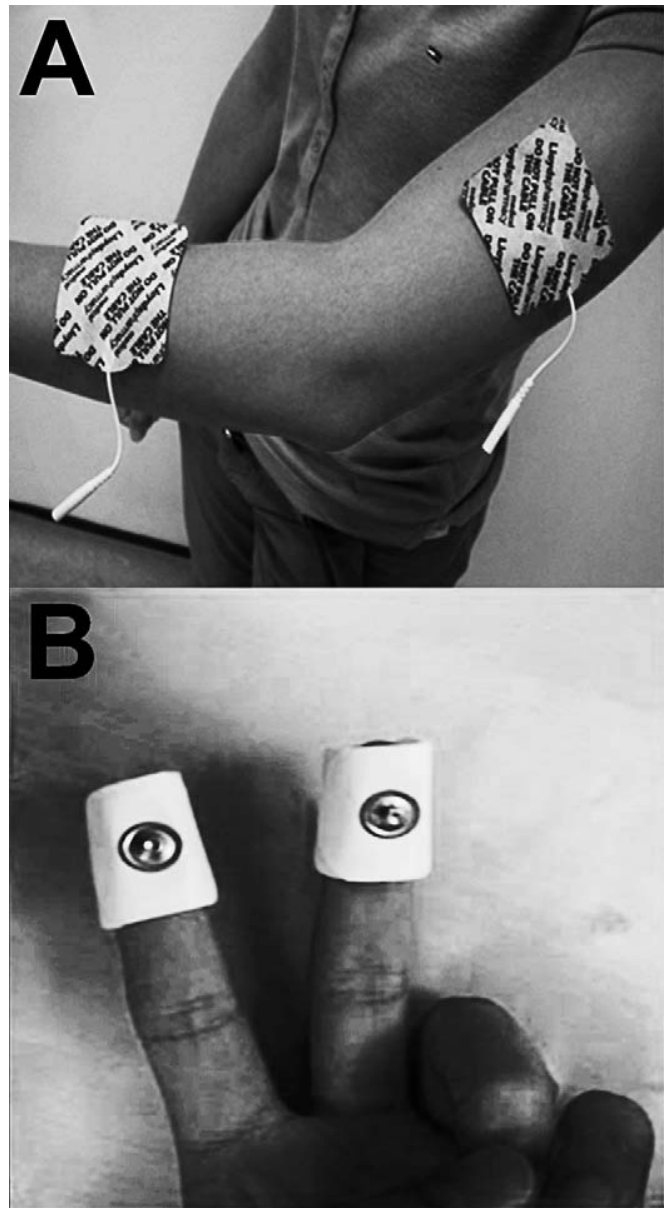

Figure 1. (A) Placement of TENS electrodes on the subject's dominant arm. (B) The GSR electrode placement on the subject's nondominant hand.

inch Sony CRT monitor (Model $\mathrm{N}^{\circ}$ GDM-F520; Sony Corporation, Tokyo, Japan) was positioned behind the motorized mirror and reflected through another mirror placed behind the subject at the other end of the lab, providing a total viewing distance of $7 \mathrm{~m}$ (i.e., after reflection by both mirrors).

\section{Nystagmus Recording and Analysis}

Eye movements were recorded using an infrared limbus tracker (IRIS; Skalar Medical BV, Delft, The Netherlands). This system has high spatial $\left(0.1^{\circ}\right)$ and temporal $(1000 \mathrm{~Hz})$ resolution, and is linear within $3 \%$ up to $\pm 25^{\circ}$ horizontally. ${ }^{28}$ To calibrate the IRIS, the motorized mirror was driven repeatedly through $\pm 10^{\circ}$ (i.e., evoking $\pm 20^{\circ}$ eye movements) for 40 seconds at $0.25 \mathrm{~Hz}$ while subjects fixated a black spot subtending $0.2^{\circ}$ on the monitor. Subjects were asked to fixate the target as accurately as possible throughout. The IRIS output was calibrated by plotting a regression of instantaneous output voltage against target position. Thus, eye position during nystagmus was measured at each time point sampled and regressed against target position. A Pearson's coefficient of $>0.85$ was required for an acceptable calibration.

\section{Experimental Procedure}

Subjects first fixated a black spot target in the center of the monitor for 5 minutes to test for the presence of periodic

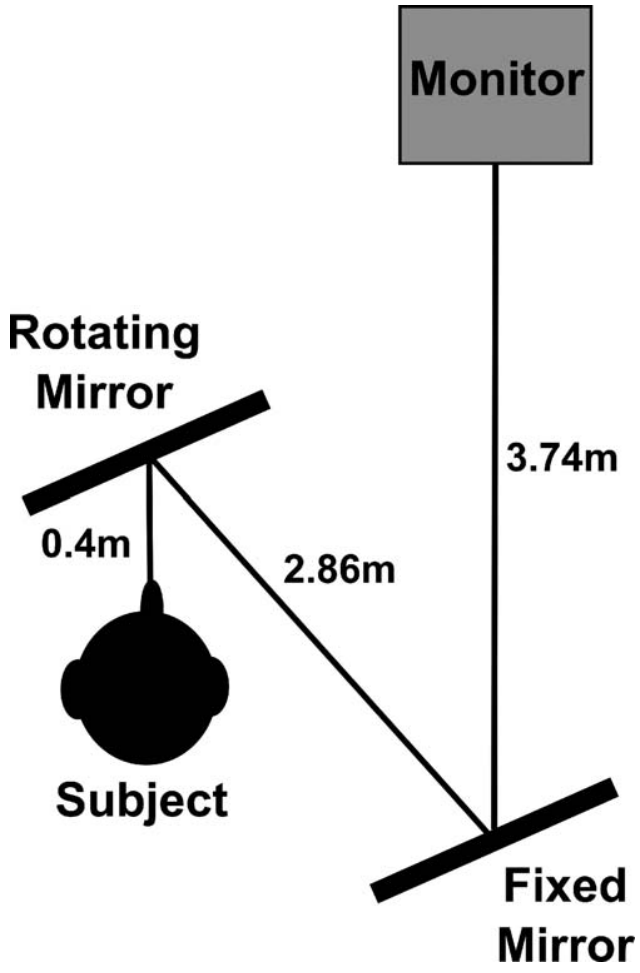

Figure 2. Schematic of laboratory setup. The angle of the rotating mirror was adjusted for each patient to shift the image into the patient's null zone.

alternating nystagmus (PAN). ${ }^{29}$ None of the subjects reported in this study demonstrated PAN. The VA task then was repeated four times in the following sequence of conditions, each lasting 60 seconds: acclimatization (A), task demand (TD), anticipatory anxiety (AA), and relaxed (R).

During the TD period, subjects received a short burst ("shock") from the TENS machine when they provided an incorrect response to the VA task. Obviously, this resulted in very few shocks at the start, but progressively more as the subjects approached VA threshold (average $0.11 \mathrm{~Hz}$ ). During the AA period, subjects received a short burst from the TENS machine independent of their responses, at a frequency of approximately $0.02 \mathrm{~Hz}$. During both periods, subjects were told that the burst from the TENS machine would be at double their threshold. This never was actually the case, as the TENS was set simply to a different mode (one in which the frequency of the burst was higher) so that subjects would perceive a difference.

The order of the four conditions was the same for all subjects, and $\mathrm{SkC}$ was measured continuously for the entire duration of the experiment.

\section{Nystagmus Parameters}

In each condition, VA was taken as the average of the last 8 reversals. A continuous 6-second period of nystagmus was chosen when the VA was at threshold (i.e., midway between the first and last reversals), which typically included approximately 24 cycles of nystagmus $(4 \mathrm{~Hz})$. Slow phases were identified manually, and their duration and amplitude were calculated from the end of the last quick-phase to the beginning of the next quick-phase. Frequency was computed as the reciprocal of the mean duration of complete cycles (i.e., slow and quick phases) during the 6-second period. Intensity was the product of amplitude and frequency. 


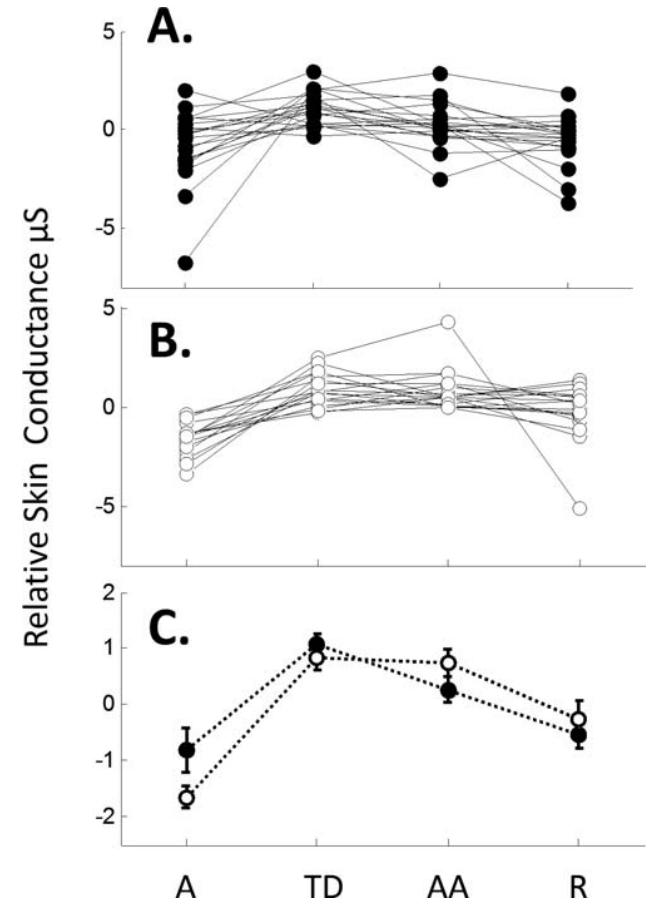

Figure 3. Effect of condition on relative SkC for people with INS (solid circles) and controls (open circles). (A) The mean SkC was measured over each condition for 20 patients. Each point is the relative SkC where each subject's mean across the four conditions is subtracted (see Methods) and lines join the same subject's SkC. Note the general increase in SkC for the shock conditions, TD and AA. Variability in the initial A period is higher than in the final $\mathrm{R}$ period. (B) Same as (A), but displays data of the 17 controls. Note less variability during A period. (C) Grand means for (A) and (B) clearly showing increased SkC in the shock conditions. Error bars are \pm 1 SE.

The FPs were measured using a bespoke program written using MATLAB (MathWorks, Natick, MA), which detected periods of the waveform when velocity was $\leq 4^{\circ} / \mathrm{s}$ and position was within $\pm 2^{\circ}$ of target position..$^{5,8,12,13}$

\section{Statistical Analysis}

The first acclimatization period (A) was used to reduce incoming anxiety and minimize any learning effects in the experimental procedure. For statistical analysis of nystagmus parameters and visual function, we excluded the A period and used the $\mathrm{R}$ period at the end of each experiment for comparison with the two preceding conditions, TD and AA.

Amplitude, intensity, and FPs were not distributed normally (Shapiro-Wilk test), and a $\log$ transform was applied to normalize the data. Because these parameters (i.e., amplitude, frequency, intensity, and FPs) were highly correlated, we used a $(3 \times 4)$ multivariate ANOVA (MANOVA) to test for condition (TD, AA, R) and the four parameters. Principal component analysis then was based on the correlation matrix of the 4 parameters. The first 2 factors were kept and rotated using the varimax procedure. New scores, called factor 1 and factor 2, were generated and tested separately using repeated measures ANOVA. SPSS version 20 (SPSS, Inc., Chicago, IL) was used for all analyses (see Results).

For RTs, we calculated the median for each condition, and used nonparametric analysis. The patient and control groups were compared (collapsed across TD, AA, and R) with the Mann-Whitney $U$ test. The conditions TD versus AA and AA versus $\mathrm{R}$ were compared in both groups separately with the Wilcoxon signed rank sum test. Using a Bonferroni correction for 5 tests (at $\alpha=0.05$ ), we set each test significance level to $\alpha$ $=0.0102$

\section{Results}

\section{Effect of Shock on SkC}

Overall, relative SkC was significantly sensitive to condition $\left(F_{[3,108]}, P<0.001\right.$; Fig. 3). Typically, SkC was higher during the TD and AA conditions, and lower during the rest conditions, A and R. Sequential comparisons showed that A and TD were significantly different $\left(F_{[1,36]}, P<0.001\right)$, as were TD and AA $(P<0.019)$, and AA and R $(P<0.006)$. We concluded that the electric shock was effective in raising arousal, and that TD was more effective than AA.
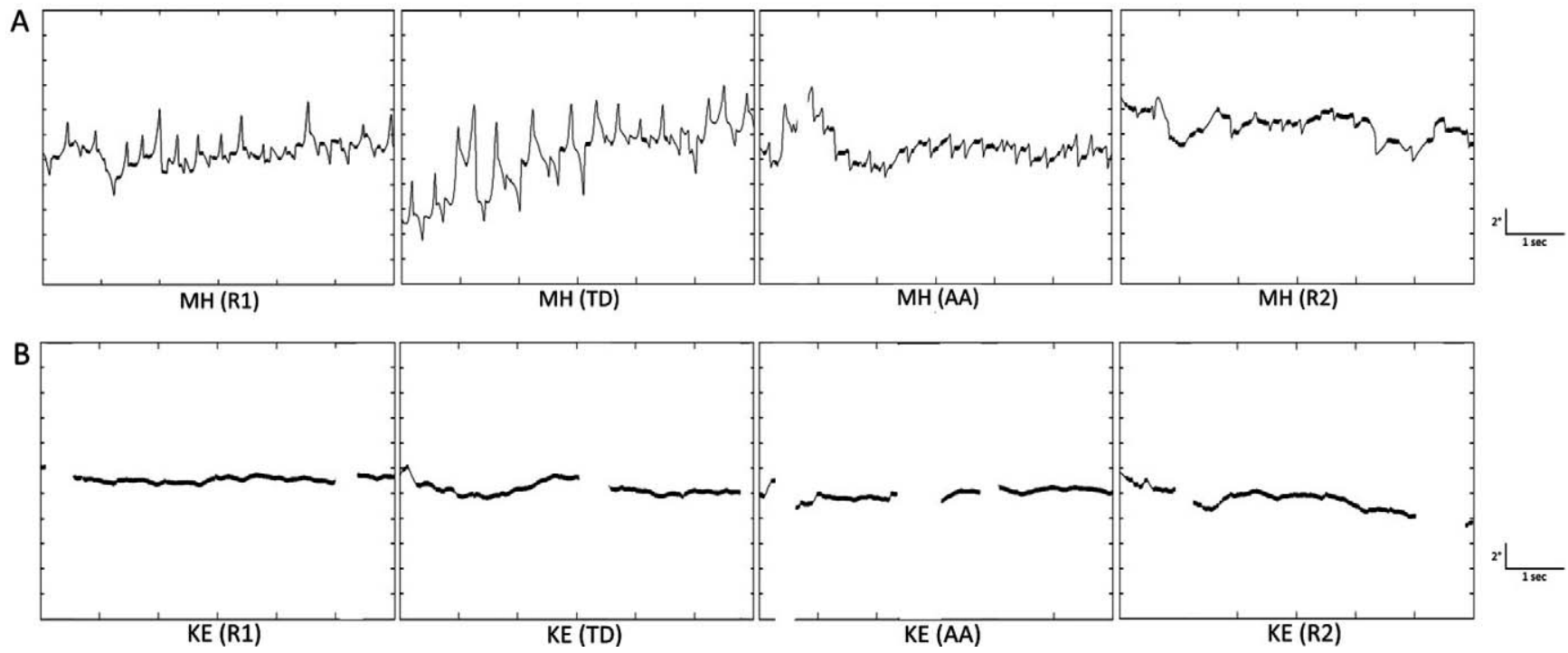

FiguRE 4. Typical eye movement traces showing eye position over time across all of the experimental periods for (A) subject with INS and (B) control subject. Gaps in traces show blinks. 

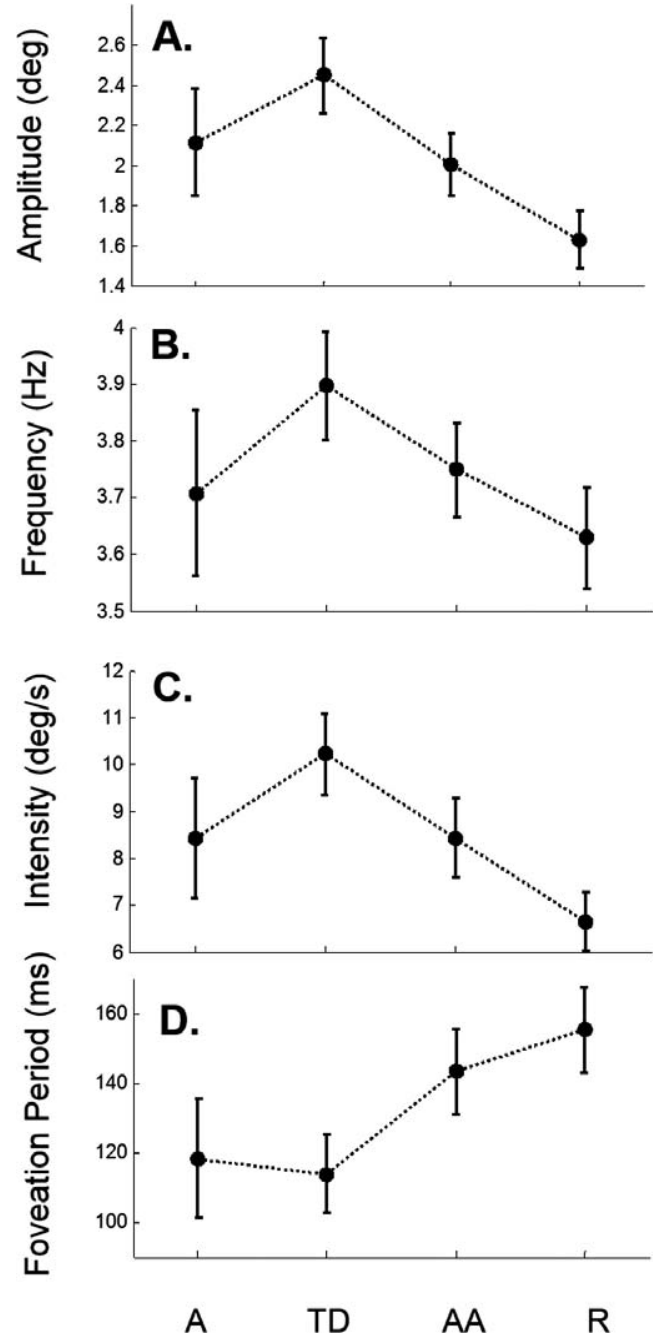

Figure 5. Effect of condition on nystagmus parameters for 23 subjects. Each point represents grand mean (across all patients) for (A) amplitude, (B) nystagmus frequency, (C) nystagmus intensity, (D) FPs (see Methods). Error bars are \pm 1 SE. Severity of nystagmus is highest for the contingent shock condition (TD). Note higher variability and mean for the initial A condition, compared to the final $\mathrm{R}$ condition, presumably reflecting individual differences in initial stress in subjects with INS

The nystagmus group (solid circles in Fig. 3A) showed more variability than the control group (open circles in Fig. 3B), especially during the initial period $\mathrm{A}$, during which patients tended to be relatively more aroused than controls. The A condition probably reflected uncontrolled individual difference in arousal for the subjects as they became accustomed to the experimental surroundings, and, therefore, condition A subsequently was excluded from analysis.

\section{Effect of Shock on Nystagmus}

The effect of shock on nystagmus was seen clearly in individual eye movement traces (see example in Fig. 4). During the TD condition, nystagmus amplitude and frequency typically increased, and usually were least in R (Fig. 5).

To quantify the nystagmus, we first considered nystagmus amplitude, frequency, intensity, and FPs collectively as correlated measures. We included means of these 4 variables for each patient in 3 conditions (TD, AA, and $\mathrm{R}$ ) in a $4 \times 3$ MANOVA (see Methods). Overall, the nystagmus was affected

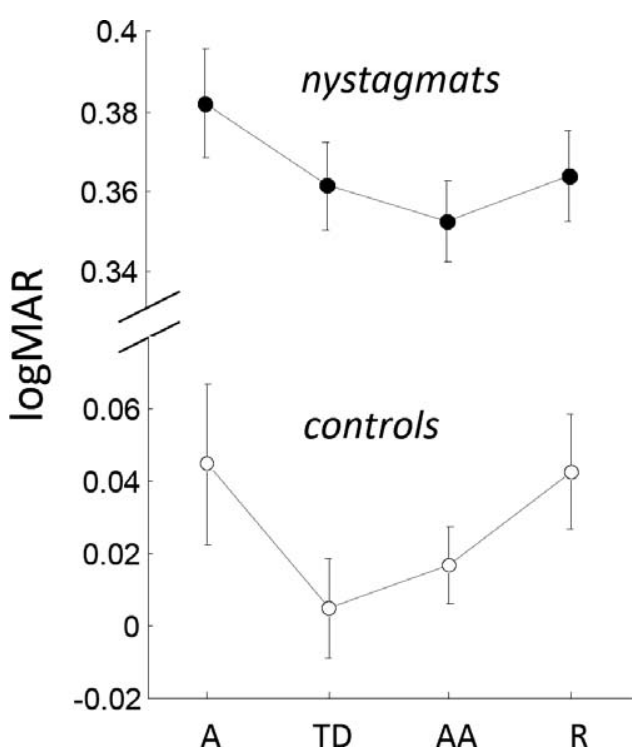

Figure 6. Effect of conditions on VA (see Methods) for subjects with INS (solid circles) and controls (open circles). Shock does not reduce VA. Error bars are \pm 1 SE.

significantly by the condition $\left(F_{[8,84]}=2.1, P<0.045\right)$, with significant measures being nystagmus amplitude $\left(F_{[2,44]}=5.7\right.$, $P<0.01)$, intensity $\left(F_{[2,44]}=6.4, P<0.007\right)$, and FPs $\left(F_{[2,44]}=\right.$ 5.0, $P<0.022$ ). Nystagmus frequency exhibited the most variability and was not affected significantly by condition $\left(F_{[2,44]}=2.1, P<0.14\right)$.

These measures were highly correlated, and a principal components analysis (collapsed across all conditions) revealed a dominant factor (factor 1 ) that explained $80 \%$ of the variance (eigenvalue $=3.2$ ) and minor factor (factor 2) explaining $16.5 \%$ of variance (eigenvalue $=0.66$ ). The remaining two factors accounted for less than $4 \%$ of variance and were discarded. After rotation (varimax), factor 1 was heavily weighted by amplitude (0.98), intensity (0.88), and FPs $(-0.75)$, but weakly by frequency $(0.23)$, whereas factor 2 had weights in the opposite order $(0.13,0.46,-0.58,0.96)$. Factor 1 was significantly dependent on condition $\left(F_{[2,44]}=4.9, P<\right.$ 0.012) with TD (but not AA) being significantly different from $\mathrm{R}\left(F_{[1,22]}=7.1, P<0.014\right)$. Factor 2 was not significantly affected by condition $\left(F_{[2,44]}=0.28, P<0.76\right)$, and appeared to reflect a component dominated by nystagmus frequency. The same factors with similar eigenvalues and weights also occurred within each condition; hence, their relative strengths were not a result of their differential sensitivity to stress.

In summary, the parameters of nystagmus were affected significantly by the stress produced by contingent shock (TD). We also concluded that increases in amplitude and/or intensity are associated with shorter FPs (see Fig. 5). There also existed a nonsignificant minor factor determined mostly by nystagmus frequency.

\section{Effect of Shock on Visual Function}

The effect of shock-induced stress on VA is shown in Figure 6 for both groups. Clearly, subjects with INS had poorer VA than controls. However, for both groups, VA actually improved slightly ( 0.03 LogMAR) with shock. This is a small, but plausibly real, effect that might emerge as significant with a larger sample size. Thus, if we included the initial A condition, the improvement in mean VA for the two stress conditions (TD and AA combined) over the mean of the shock-free conditions (A and $\mathrm{R}$ ) was borderline significant $(P<0.045)$. More 


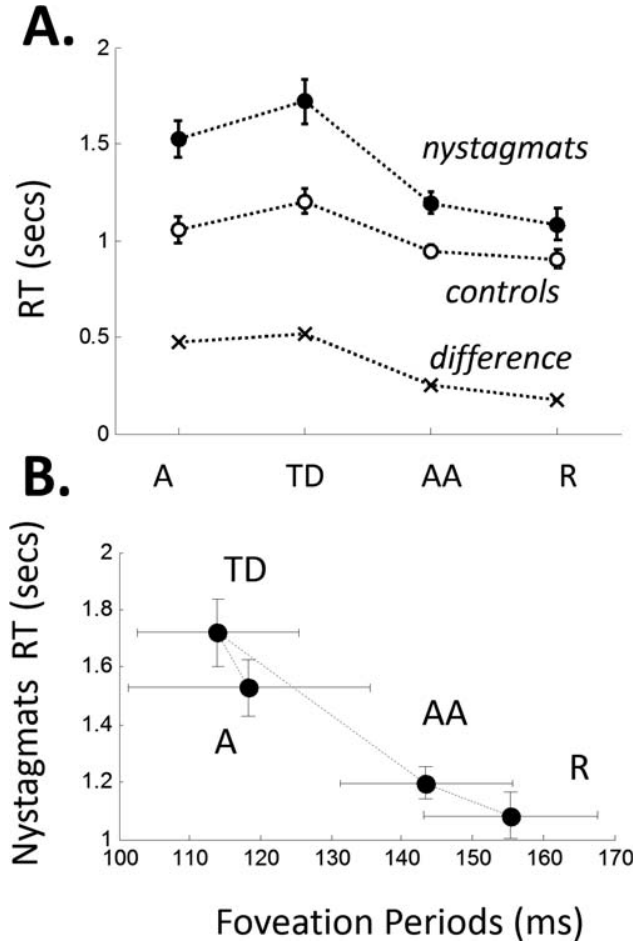

Figure 7. (A) The RTs for subjects with INS (solid circles) and controls (open circles). Similar patterns, showing an increase in RT with contingent shock (TD), are seen for both groups with the difference (crosses) indicating a greater impact on INS (see text for discussion). (B) Plot of RTs of INS subjects versus mean FP. Error bars are $\pm 1 \mathrm{SE}$.

importantly, stress, more intense nystagmus, and reduced FPs do not result in reduced VA (see Discussion).

The RT was measured as the time it took subjects to respond to the visual stimulus following its appearance on the monitor (Fig. 7A). People with INS took significantly longer than controls to respond during the TD, AA, and $\mathrm{R}$ conditions (Mann-Whitney $U$ test, $P<0.0005$ ). The TD was significantly longer than AA in both groups (Wilcoxon; patients, $P<0.009$; controls, $P<0.004$ ), but AA was not significantly different from R (Wilcoxon; patients, $P<0.28$; controls, $P<0.35$ ). In contrast to VA, RT was correlated strongly with FPs (Fig. 7b).

\section{Discussion}

Recording skin conductance (electrodermal response, galvanic skin resistance [GSR]) is a well-established technique for measuring autonomic arousal, which measures changes in electrical resistance of the eccrine sweat glands that are innervated by the sympathetic pathway. Electric shock is a powerful stressor even at harmless levels, and the arousal is readily detectable by GSR. We found that nystagmus beat amplitude and intensity increased during the contingent shock period (TD), but to a lesser extent during noncontingent shock (AA), and subsided in the final relaxed period (R; Figs. 5a, 5c). We also found a similar decrease in the duration of FPs under stress. However, these measures are highly correlated and appear to reflect two underlying processes (factors 1 and 2). In factor 1, amplitude is the dominant factor associated with intensity and FPs, and is sensitive to the stressor. In factor 2, frequency is the dominant factor associated with intensity and FPs, but appears to be insensitive to the stressor. Further studies are needed to elaborate these factors. In any case, we concluded that INS is sensitive to sympathetic arousal, consistent with the findings of Cham et al. ${ }^{19}$

It would seem intuitive that reduced FPs should reduce VA, but Cham et al. ${ }^{19}$ reported no such reduction; however, their study was not designed to measure VA per se. In our study, we used standard optotypes, and found a small increase in VA during stress, which also was evident in the control group. We concluded, therefore, that the stress-induced increase in nystagmus intensity (and reduction in FPs) does not reduce VA. This result seems at odds with expectation and previous work. However, the majority of studies that have related VA or contrast sensitivity to specific nystagmus waveform parameters have not manipulated the nystagmus waveform within subjects, but only across subjects. ${ }^{11,30-32}$ In biofeedback studies within subjects, VA has been reported to improve with reduced nystagmus, but the effect is small. ${ }^{33}$ Even studies purported to predict VA from foveation ${ }^{9,34}$ appear to be based on a between-subjects correlation, and not on changes in VA within individuals.

A possible explanation for the increase in VA with stress emerges when we examine RTs, which did increase significantly with stress (Fig. 7). Consider, first, the control group. The median RT was approximately one second, implying that temporal summation extends far beyond the human visual integration time. It has been shown that partial temporal summation can occur up to 3 seconds or more. ${ }^{35,36}$ Summation also can occur when stimulus exposure is split into two separate periods. ${ }^{37}$ Adrian $^{36}$ modeled this extended speedaccuracy trade-off given by: $V A=0.57 \log _{10}(C \times T)+1.705$, where $C$ is contrast and $T$ is exposure time $(C \times T$ is total contrast dose). We propose that, when controls were punished for incorrect responses with contingent electric shock (TD), RTs increased because of a shift in criterion to more accurate responses, and, hence, increased acuity. If we assume that our response times include approximately 0.2 seconds movement time to press a button, then the mean exposure times (decision time) for the control group ranged from approximately 0.7 to approximately 1.0 seconds. Substituting into Adrian's formula, the increase in exposure time would yield an improved acuity of $\sim 0.025$ LogMAR, for a high contrast Landolt C, which is in reasonable agreement with our observation (Fig. 6).

For the INS group, the extended exposure can be accrued only across sequential FPs, and, hence, cycles of nystagmus. Since much time during a nystagmus cycle usually is spent outside the foveation window, overall RTs are much higher for nystagmats. As with the controls, there is a shift to longer exposure to improve accuracy with contingent shock leading to an increase in overall RTs. Cham et al. ${ }^{19}$ also reported a similar magnitude of VA decrease in their restricted viewing task. However, the shock also acts as a stressor for the nystagmats, and reduces FPs (presumably via sympathetic pathways). Thus, even more nystagmus cycles are needed to accrue the requisite exposure time. Overall, this has some important ramifications.

First, if a nystagmat were to take unlimited time to respond, then VA should reach its maximum asymptotic value, which is determined by optics and neural pathways (refractive errors, sensory defects, amblyopia, and so forth). Manipulating the waveform (biofeedback, stress/relaxation, drugs, muscle surgery, null-eccentric viewing, and so forth) then will have only a negligible effect on VA, because the patient is at asymptotic VA. In reality, subjects (and controls) do not take infinite time, but will set a criterion depending on their understanding of task demand. However, if the subject expects to perform well without overt time restrictions (as occurs typically in a clinical setting), then VA will be only mildly affected by waveform manipulations, because the patient will increase or reduce their RTs to reach a desired accuracy. Under such manipula- 
tions (within subject), the durations of FPs would be only weakly or not correlated to VA, as observed empirically (see Introduction). In this scenario, VA may be a good measure of any underlying limit to the sensory pathway, but a relatively poor outcome measure in clinical trials that manipulate nystagmus waveform (e.g., drugs or muscle surgery).

On the other hand, if the patient is under pressure to respond quickly (e.g., driving, crossing roads, and so forth), or exposure time is restricted experimentally, then manipulating waveform may affect VA depending on the accrued foveation time. This is consistent with a study showing that restricted exposure time has a relative detrimental effect on VA in eccentric gaze for INS patients, ${ }^{38}$ presumably because nystagmus is more intense (shorter FPs) when gaze is away from the average null zone. Increasing FPs would increase VA if the nystagmus cycle duration (beat frequency) remained unchanged, since there would be more foveal exposure time per second. However, if the cycle duration also increased, VA may be unaffected or even decrease. The problem is complex, depending on absolute FP durations, FP duty cycle, and underlying contrast sensitivity.

We emphasize that this study is not directly comparable to the "slow-to-see" phenomenon reported by Wang and Dell'Osso. ${ }^{21,39}$ First, they recorded refixations to peripheral visual targets and measured the latency after a saccade of the first FP that was on target, and followed by successive accurate foveations. In our study, participants were fixating the central screen and were not required to make saccades (beyond their usual fast phases). Second, Wang and Dell'Osso ${ }^{21}$ did not measure any perceptual component, but only examined eye movement traces. It is impossible to infer how long their subjects took to perceive or make a cognitive decision about the peripheral target. Based on our study, it can take a number of on-target FPs before a decision is made. We argue that their study reports "slowness to foveate a peripheral target," and ours reports "slowness to make a visual decision." The term "slow-to-see" is potentially misleading.

Our study has helped to clarify the role of stress in INS, but it raises an even more fundamental question. Waveforms can change dramatically in patients with INS, but this and previous studies, for example, ${ }^{18,19}$ do not find a corresponding change in VA. As we have discussed, VA is largely insensitive to waveforms. However, the puzzle is why some studies report strong correlations between FPs and VA across subjects. ${ }^{11,32,40}$ One possibility is that we have misunderstood the causal relationship between waveform and vision, such that VA is more or less fixed for an individual (due to sensory defects, amblyopia, unknown developmental reasons, and so forth), and that the waveform of a given subject adapts to the underlying VA. Wiggins et al. ${ }^{18}$ reported some degree of plasticity, in which FPs increased with increased target resolution ("visual demand"). Thus, it is conceivable that the waveform is fine-tuned to optimize visual task performance. For example, as proposed previously, contrast for high spatial frequencies is optimized by long FPs, but not necessarily for low spatial frequencies. ${ }^{18,41}$ For a VA task with unrestricted viewing, a nonoptimal waveform only has minor effects on VA, as VA is close to asymptote (see above), but this may not be the case for other tasks and clearly this issue must be explored further.

In summary, we propose that phrases, such as "effort to see," "fixation effort," "visual demand," "task demand," "slow-to-see," are ill-defined and subject to misinterpretation. Even the term "stress" is difficult to define outside the context of physiologic sympathetic arousal. The use of these terms in the literature should, in future, be defined more carefully and precisely to test their implication properly for those with nystagmus. We concluded that sympathetic arousal (adminis- tered by electric shock and measured by SkC) strongly affects nystagmus waveforms and reduces FPs. However, this has little resulting impact on VA. The increase in RT seen with stress probably is a result of two mechanisms: (1) by shifting criteria to more accurate responses (and, hence, the slightly improved VA reported here), and (2) by shortening FPs and, hence, increasing the number of nystagmus cycles needed to reach the response criterion. This has implications for those with nystagmus in the real world as discussed above. We also suggested that VA alone is likely to be an insufficient measure of visual function for those with nystagmus. As a result, VA should be combined with other measures, such as "response time," to give a more complete picture of visual performance. More research now is needed to investigate these findings further.

\section{Acknowledgments}

The authors thank Paul Farrugia and Denley Slade for designing and fabricating the rotating mirror system, and Nathan Bromham for programming the controlling software.

Supported by the College of Optometrists, London, United Kingdom.

Disclosure: P.H. Jones, None; C.M. Harris, None; J.M. Woodhouse, None; T.H. Margrain, None; F.A. Ennis, None; J.T. Erichsen, None

\section{References}

1. Lorenz B, Gampe E. Analysis of 180 patients with sensory defect nystagmus (SDN) and congenital idiopathic nystagmus (CIN). Klin Monbl Augenbeilkd. 2001;218:3-12.

2. Abadi RV, Bjerre A. Motor and sensory characteristics of infantile nystagmus. Brit J Opbthalmol. 2002;86:1152-1160.

3. Dell'Osso LF. Fixation characteristics in hereditary congenital nystagmus. Am J Optom Arch Am Acad Optom. 1973;50:8590.

4. Dell'Osso LF, Daroff RB. Congenital nystagmus waveforms and foveation strategy. Doc Opbthalmol. 1975;39:155-182.

5. Dell'Osso LF, Vandersteen J, Steinman RM, Collewijn H. Foveation dynamics in congenital nystagmus. 1. Fixation. Doc Opbthalmol. 1992;79:1-23.

6. Erchul DM, Dell'Osso LF, Jacobs JB. Characteristics of foveating and defoveating fast phases in latent nystagmus. Invest Opbthalmol Vis Sci. 1998;39:1751-1759.

7. Leigh RJ, Zee DS. The Neurology of Eye Movements. 3rd ed. London, UK: Oxford University Press; 1999:646.

8. Cesarelli M, Bifulco P, Loffredo L, Bracale M. Relationship between visual acuity and eye position variability during foveations in congenital nystagmus. Doc Opbthalmol. 2000; 101:59-72.

9. Dell'Osso LF, Jacobs JB. An expanded nystagmus acuity function: intra- and intersubject prediction of best-corrected visual acuity. Doc Opbthalmol. 2002;104:249-276.

10. Dickinson CM, Abadi RV. The influence of nystagmoid oscillation on contrast sensitivity in normal observers. Vision Res. 1985;25:1089-1096.

11. Bedell HE, Loshin DS. Interrelations between measures of visual-acuity and parameters of eye-movement in congenital nystagmus. Invest Ophthalmol Vis Sci. 1991;32:416-421.

12. Bifulco P, Cesarelli M, Loffredo L, Sansone M, Bracale M. Eye movement baseline oscillation and variability of eye position during foveation in congenital nystagmus. Doc Opbthalmol. 2003;107:131-136.

13. Dell'Osso LF, Averbuch-Heller L, Leigh RJ. Oscillopsia suppression and foveation-period variation in congenital, latent, and acquired nystagmus. Neuro-Ophthalmol. 1997;18:163-183. 
14. Dell'Osso LF. Congenital nystagmus: basic aspects. In: Lennerstrand G, Zee D, Keller EL, eds. Functional Basis of Ocular Motility Disorders. Stockholm, Sweden: Pergamon Press; 1982:129-138.

15. Dell'Osso LF, Flynn JT, Daroff RB. Hereditary congenital nystagmus - intrafamilial study. Arch Ophthalmol. 1974;92: 366-374.

16. Abadi RV, Dickinson CM. Wave-form characteristics in congenital nystagmus. Doc Ophthalmol. 1986;64:153-167.

17. Tkalcevic LA, Abel LA. The effects of increased visual task demand on foveation in congenital nystagmus. Vision Res. 2005; 45:1139-1146.

18. Wiggins D, Woodhouse JM, Margrain TH, Harris CM, Erichsen JT. Infantile nystagmus adapts to visual demand. Invest Ophthalmol Vis Sci. 2007;48:2089-2094.

19. Cham KM, Anderson AJ, Abel LA. Task-induced stress and motivation decrease foveation-period durations in infantile nystagmus syndrome. Invest Ophthalmol Vis Sci. 2008;49: 2977-2984.

20. Cham KM, Anderson AJ, Abel LA. Oscillopsia and the influence of stress and motivation in fusion maldevelopment nystagmus syndrome. Invest Ophthalmol Vis Sci. 2013;54:2004-2010.

21. Wang ZI, Dell'Osso LF. Being "slow to see" is a dynamic visual function consequence of infantile nystagmus syndrome: model predictions and patient data identify stimulus timing as its cause. Invest Ophthalmol Vis Sci. 2007;47:1550-1560.

22. Sprunger DT, Fahad B, Helveston EM. Recognition time after four muscle recession for nystagmus. Am Orthoptic J. 1997; 47:122-125.

23. Gray M, Kemp AH, Silberstein RB, Nathan PJ. Cortical neurophysiology of anticipatory anxiety: an investigation utilizing steady state probe topography (SSPT). Neuroimage. 2003;20:975-986.

24. Chua P, Krams M, Toni I, Passingham R, Dolan R. A functional anatomy of anticipatory anxiety. NeuroImage. 1999;9:563571.

25. Speilberger CD, Sarason IG. Stress and Anxiety. Washington D.C.: Hemisphere Publishing Corporation; 1975:335.

26. Golding JJ, Marsh R, Ashton H, Thompson JW. Changes in short and long latency somatosensory evoked-potentials (SEPS) following trans-cutaneous electrical nerve stimulation (TENS) - individual differences and implications for mechanisms. Biol Psychol. 1985;21:255-256.
27. Want S. Lloyds Pharmacy - Digital Pain Reliever Users Manual. Coventry, UK: Lloyds Pharmacy; 2007.

28. Reulen JPH, Marcus JT, Koops D, et al. Precise recording of eye-movement: the IRIS technique .1. Med Biol Eng Comput. 1988;26:20-26.

29. Shallo-Hoffmann J, Faldon M, Tusa RJ. The incidence and waveform characteristics of periodic alternating nystagmus in congenital nystagmus. Invest Ophthalmol Vis Sci. 1999;40: 2546-2553.

30. Abadi RV, Sandikcioglu M. Visual resolution in congenital pendular nystagmus. Am J Optom Physiol Opt. 1975;52:573581.

31. Pascal E, Abadi RV. Contour interaction in the presence of congenital nystagmus. Vision Res. 1995;35:1785-1789.

32. Abadi RV, Worfolk R. Retinal slip velocities in congenital nystagmus. Vision Res. 1989;29:195-205.

33. Ciuffreda KJ, Goldrich SG, Neary C. Use of eye movement auditory biofeedback in the control of nystagmus. Am J Optom Physiol Opt. 1982;59:396-409.

34. Sheth NV, Dellosso LF, Leigh RJ, Vandoren CL, Peckham HP. The effects of afferent stimulation on congenital nystagmus foveation periods. Vision Res. 1995;35:2371-2382.

35. Legge GE. Sustained and transient mechanisms in human vision: temporal and spatial properties. Vision Research. 1978;18:69-81.

36. Adrian $\mathrm{W}$. The effect of observation time and contrast on visual acuity. Clinical and Experimental Optometry. 2003;86:179182.

37. Baron WS, Westheimer G. Visual acuity as a function of exposure duration. J Opt Soc Am. 1973;63:212-219.

38. Yang DS, Hertle RW, Hill VM, Stevens DJ. Gaze-dependent and time-restricted visual acuity measures in patients with infantile nystagmus syndrome (INS). Am J Ophthalmol. 2005;139:716718 .

39. Wang ZI, Dell'Osso LF. Factors influencing pursuit ability in infantile nystagmus syndrome: target timing and foveation capability. Vision Res. 2009;49:182-189.

40. Chung STL, Bedell HE. Congenital nystagmus image motion: influence on visual acuity at different luminances. Optom Vis Sci. 1997;74:266-272.

41. Harris C, Berry D. A developmental model of infantile nystagmus. Sem Ophthalmol. 2006;21:63-69. 